\title{
Supporting Young Children's Learning in a Dramatic Play Environment
}

\author{
Janine Hostettler Scharer
}

\begin{abstract}
Janine Hostettler Scharer, PhD, educational psychology from Simon Fraser University, is a lecturer for university and college-level classes in early childhood education and a former kindergarten teacher. Her research interests include learning and development in families and early childhood settings, relationships, and play. Her dissertation explored children's transitions from family to childcare. Email: janine.hostettler@gmx.net
\end{abstract}

Vygotsky and his followers believe that makebelieve play is the leading activity in preschool, kindergarten, and the early primary grades. Play-based curricula are common in early childhood classrooms today, but what does this look like in practice? Does it mean that children get some time for free play in centres between blocks of direct instruction? What could learning in a play-learning environment look like? Prospective ECE teachers often show difficulty integrating play for learning. In their experiences, play is often something to do in between their guided instruction. In this paper I challenge those beliefs and show, based on an example, how learning and teaching are possible through play when the whole classroom is transformed into a museum. Teachers will not only be addressing curricular goals, but also encouraging imagination, creativity, social development, and many other learning goals at the same time. Based on Vygotsky's theory on play, I present ways to enrich, support, and foster play while learning within a play-learning environment.

Key words: early childhood education; dramatic play; curriculum; play-learning environment
As an early childhood education lecturer at both the university and college level and a former kindergarten teacher, I have been experiencing, studying, and researching children's play and have always been fascinated by it. In my graduate studies, I was particularly drawn to Vygotsky's (1978) cultural-historical theory. I explored what Vygotsky wrote about mature dramatic play as leading a child's development and incorporated those views in my lectures. However, when teaching prospective ECE teachers and educators about play and learning through play, I faced more challenges than I anticipated. I have observed prospective ECE teachers being as fascinated by Vygotsky's play theory as I, and being astonished by the potential for children to learn through play. Nonetheless, many prospective ECE teachers I have worked with (especially ones teaching kindergarten and elementary grades but also some prospective preschool teachers) hold the preconception that play is something they can allow children to do between blocks of instruction, something that children will do unprompted and that does not need their input, something that gives teachers or educators time to do other things. These prospective teachers' idea of play was either centre time (playing house, blocks, reading corner) or outdoor play (playground time). I found that even when these prospective teachers learn about the benefits of learning through play, they still worry about parental opposition to playtime in the classroom and that playtime will take away from their ability to complete their curriculum. My objective is to challenge these beliefs.

What I am presenting is based on a Vygotskian theory of play that focuses on dramatic or make-believe play. I will discuss how play develops, how play is considered the leading activity of preschoolers and early elementary children, how play influences development, and how teachers and educators can foster, enrich, and scaffold mature dramatic play. The preschool period in Vygotsky's terms is the time between a child's third and seventh birthdays, therefore it includes kindergarten and early primary grades. After presenting this theoretical approach, I will 
address some common concerns of prospective teachers and educators by introducing an example of a playlearning environment (PLE) and explaining how curricula competencies can be taught and assessed in such a dramatic play environment.

\section{A Vygotskian Definition of Play}

In Vygotsky's cultural-historical theory, play is an important part of early childhood. Vygotsky believed that play promotes cognitive, social, and emotional development in children. However, the Vygotskian view on sociodramatic play is just the opposite of the common belief that play is children's free activity time in which they do whatever they want while liberating themselves from rules and social pressure (Karpov, 2003). In the Vygotskian definition, play is limited to the dramatic or make-believe play of preschoolers. Vygotsky's play theory therefore differs from other play theories, which also include object-oriented exploration, constructional play, and games with rules. Real play activities, according to Vygotsky, include the following components: (a) creating an imaginary situation, (b) taking on and acting out roles, and (c) following a set of rules determined by specific roles (Bodrova \& Leong, 2007).

In Vygotsky's play, role-playing and the imaginary situation are planned ahead and there are rules for participating in play. Each imaginary situation has a set of roles and rules. Roles are the characters children play and rules are the behaviours allowed by either role or play scenario. Roles are often explicit and can be seen through the children's behaviour. In the beginning, rules are often hidden in the play (i.e., they cannot be observed easily), but later the rules become explicit and are negotiated by the children. Further, when playing, children place constraints on their own behaviour, which marks the beginning of self-regulation (Bodrova \& Leong, 2007).

When children are around 3 years old, they develop a strong interest in the world of adults, and they want to become a part of this world. Because this desire cannot be fulfilled directly (i.e., children cannot become a firefighter or a doctor), they enter the world of adults through imitation and exploration of social relationships through dramatic play (Karpov, 2003). Vygotsky believed that children are able to engage in pretend play because they start to separate the visual field (what can be seen) from the field of sense (what can be implied), or meaning. Through pretend play, a child can decontextualize meaning, that is, think about something even when the object is not present or evident (Smidt, 2009). In play, thought is separated from object and action starts from ideas and not from things: a piece of wood can be a doll, a stick becomes a horse. Acting according to rules begins to be determined by ideas rather than by objects, and the child's relation to the immediate, real, and concrete situation becomes revealed through play (Vygotsky, 1978). Vygotsky saw this as the first step for the development of higher mental functions and verbal thinking, which becomes important for children during their transition to school (Gajdamaschko, 2011; Karpov, 2003; Smidt, 2009).

\section{How Play Develops}

The roots of play lie in object-oriented activities of toddlers. During manipulative situations, children explore an object's physical properties and how they are used. Later, when children use everyday objects in imaginary situations, play emerges (Bodrova \& Leong, 2007). The initial play situation is very close to the real one; it is merely a reproduction of the real situation. A child playing with a doll repeats almost exactly what the mother does with her baby; there is very little imagination. It is an imaginary situation, but only comprehensible through the real situation. Therefore, it is more memory in action than an imaginary situation (Vygotsky, 1978).

Initially, play focuses on objects. Interactions between players and their roles are of secondary importance. To qualify as play, object manipulation must include symbolic representation. Using a stick as a horse is an example 
of a symbolic representation (Bodrova \& Leong, 2007; Gajdamaschko, 2011). In another step, children act out single activities next to one another without talking to each other. Activities can happen in any order; the doll can first be dressed up and then bathed. Through action, a child makes meaning (Gajdamaschko, 2011). Later in play development, children engage in imaginary situations and can remain there. They are using play voices to indicate they are playing a role, and play becomes much more socially oriented. Children start to plan their play and set goals before they begin playing. Language becomes more important, and children can switch between their role and giving instructions. More and more roles and rules appear in one play situation, and more children can participate in the same play scenario. At the end of preschool and beginning of primary school, children start to only talk about their play and stop acting it out; time is spent negotiating roles and rules. Play as a leading activity of preschool starts to die out (Gajdamaschko, 2011) and is replaced by the learning activity (Kravtsov \& Kravtsova, 2010).

\section{Play as a Leading Activity in Preschoolers}

Because a child with no play experience is likely to show deficits in his or her cognitive and social-emotional development (Bodrova \& Leong, 2007), Vygotsky's students Leont'ev and Elkonin proposed the idea of play as the leading activity for children aged 3 to 6 years. They believed play to have a unique role for children this age which cannot be replaced by other activities, even though children benefit from a variety of other experiences during this age period (Bodrova \& Leong, 2007).

The essential characteristics that make play the leading activity of preschoolers are the importance of play for cognitive development and for the development of self-regulation (Bodrova \& Leong, 2007). Since children act out synopses of their role models' actions, they generate a model of reality, something that requires symbolic generalization. Children learn to use objects in their symbolic function and to act out symbolic representations of relationships that exist between their role models. According to Elkonin (1978, as cited in Bodrova \& Leong, 2003), in both instances the use of symbols is first supported by props and toys, and later is communicated to play partners through words and gestures. Vygotsky (1978) described play as the leading activity as follows:

Though the play-development relationship can be compared to the instruction-development relationship, play provides a much wider background for changes in needs and consciousness. Action in the imaginative sphere, in an imaginary situation, the creation of voluntary intentions, and the formation of real-life plans and volitional motives-all appear in play and make it the highest level of preschool development. The child moves forward essentially though play activity. Only in this sense can play be considered a leading activity that determines the child's development. (pp. 102-103)

In order to influence personality development, play itself must develop. Toward the end of the preschool period, when a child has mastered the main types of play, play becomes a predominant activity, an activity that influences a significant part of the child's life (Kravtsov \& Kravtsova, 2010). A certain activity is defined as leading for the given age period because mediation within this activity produces major developmental accomplishments in children and provides the basis for their transition to the next leading activity (Karpov, 2003). At the end of preschool, children become more and more interested in learning activities, a prerequisite for their transition to school.

\section{How Play Influences Development}

It has already been mentioned how play influences development through facilitating the separation of thought from actions and objects, as well as facilitating the development of self-regulation. Self-regulation in play becomes possible because a child needs to follow the rules of the play and children constantly monitor each other. Play also 
helps decentering as children learn to take other people's perspective and look at objects through the eyes of their play partner - a form of cognitive decentering (Gajdamaschko, 2011). Play also impacts the child's motivation in that a child learns to set short-term and long-term goals in play. In order to play airplane, tickets and passports need to be created, and play might not start until everything is ready (Bodrova \& Leong, 2007).

Furthermore, play is creating a zone of proximal development for many areas of children's intellectual development. Concerning play and the zone of proximal development, Vygotsky (1978) wrote that

play creates a zone of proximal development of the child. In play a child always behaves beyond his average age, above his daily behaviour; in play it is as though he were a head taller than himself. As in the focus of a magnifying glass, play contains all developmental tendencies in a condensed form and is itself a major source of development. (p. 102)

By the end of the sixth year, children's involvement in sociodramatic play results in development of a learning motive as their new leading activity. They have overcome their egocentric position toward other people and the external world, are able to self-regulate their behaviour, and are able to engage in symbolic thought, which is crucial for their success at school. Therefore, through sociodramatic play, children develop prerequisites for learning at school (Karpov, 2003).

If, by the end of the preschool age, children have not developed a fully formed activity of play, this will lead to a low level of psychological preparedness for learning in the school setting (Kravtsov \& Kravtsova, 2010). Preschoolers can get "stuck," meaning that their play actually prevents them from developing within the educational setting. Further, a lack of physical conditions that allow for the development of play can lead to situations where children do not actually learn while in school (Kravtsov \& Kravtsova, 2010). Teaching how to play is the most difficult problem in classical science, because, as Kravtsov and Kravtsova (2010) explain, "today, children are playing less and worse than in years gone by, and many adults no longer grasp the meaning and importance of the activity of play" (pp. 25-26). There is indeed less time for play in elementary classrooms, kindergarten, and preschools focusing on academic learning. However, it essential for children to learn how to play in a mature way, and teachers and educators need to know ways to foster, enrich, and scaffold play.

\section{Enriching and Scaffolding Mature Play}

In mature play, children use objects and action symbolically to represent other objects or actions. Children can pretend to have objects or pretend some action without the need to actually have it or do it. In mature play, language is used to create this pretend scenario, and themes are complex and interwoven. Children engage in the same play for an extended period of time because they are able to concentrate for a longer duration and they can use more self-regulation, planning, and memory. Children play multifaceted roles that are signalled through changes in voice, gesture, or prop (Bodrova \& Leong, 2007).

By definition, sociodramatic play is children's joint activity, but Russian neo-Vygotskians hold that adults should mediate children's play and that the major role of an adult is to present and explain different social roles to children. It is not enough to mediate children's play by giving them different toys, but rather, adults should explain the social roles that go with whatever the children are playing. Otherwise, children will not be able to play, and their sociodramatic play will be immature and impoverished (Karpov, 2003).

How can ECE teachers find ways to help children playing in an immature way to engage in play at a higher level? Prospective teachers need to differentiate between observation and interpretation of play, between what they see and what they think they see. Further, they need to know that play can be influenced through the environment, the 
toys and pivots they are using in play, the amount of time they get to play, their peers, their age, and the teachers themselves. Teachers need to find ways to assist and scaffold play processes without taking the lead. Observation of children's play is important for teachers to see a child's potential. Higher levels of play can be fostered through providing ideas for themes that extend children's experiences and through choosing appropriate toys and props. Substitutions, pivots, and pretend actions can be introduced. Teachers can help children to plan their play and monitor their progress. This can be done through supporting plots, introducing more scripts, combining actions, and introducing more children into one play situation. Children who need help have to be coached to play, and children can be encouraged to mentor each other. A teacher can suggest or model how themes can be woven together and how disputes can be resolved appropriately. Narratives and field trips help to uncover the meaning of adult life to children and support the development of scripts. Lastly, teachers need to make sure that children have sufficient time for play (Bodrova \& Leong, 2007; Gajdamaschko, 2011) as their play develops into more complex and multifaceted scenarios.

Scaffolding play development can be done by sitting close to a child and playing with the same material(s). This parallel play helps the child to concentrate longer and allows the child to take ideas by observing the teacher's play (e.g., a teacher can model the appropriate way of using tools while playing alongside a child). Another form of scaffolding is when the teacher takes a role in the children's play and only subtly tries to give input into their play (e.g., a teacher can be a visitor or customer asking questions or adding pivots that encourage children to try something new in their play). A stronger form of influence by the teacher is play tutoring. For example, if a boy wants to play at the hairdresser centre but does not know how to enter the play, the teacher could ask him, "Mr. Smith, don't you want to have a haircut? It is so warm outside already and shorter hair is much easier to handle in summer." Another form of play tutoring involves the teacher taking a role in playing with the children and leading (i.e., modelling) their play from the inside. For example, a teacher can be a cook in the restaurant and model how to read a recipe, where to look for the ingredients, and how to follow the recipe (Burkhardt Bossi, Lieger, \& von Felten, 2009).

All these possible interventions are meant to foster play activities for children. Most importantly, teachers should only intervene as long as necessary and then leave the play situation. They should not come from outside the play and ask reality-related questions, because this could break the make-believe situation and destroy the children's play.

\section{Play versus Instruction}

After considering the benefits of play, how play develops, and how play acts as the leading activity for preschool children, for prospective teachers and educators, these questions remain: How should we transfer this new knowledge surrounding play into practice? Is play beneficial enough that we as teachers need to give time for sociodramatic play in preschool, kindergarten, and early primary classrooms? Do we provide this time in between blocks of instruction, or at the end of the day? How might play be integrated within the formal curriculum? How do we justify our practice if parents want to know why we are not teaching the children academics instead? Where do we take the time?

Even if the importance of play has been understood, the benefits of play for learning taken into consideration, and our responsibility for play development recognized, prospective teachers, in my experience, are still concerned that giving more time to play will take away time they need to teach curriculum. In the following section, I want to challenge this belief and present an example of how play and instruction can be combined in a preschool, kindergarten, or early primary classroom. In a play-learning environment (PLE), learning and instruction happen through play while teachers plan, teach, and assess learning within the theme of the PLE. 


\section{Play-Learning Environments}

There are endless possibilities for play-learning environments that could be enacted in an early childhood classroom: art gallery, travel agency, train station, and restaurant, to name a few (Achermann, 2009). As an example, our kindergarten classroom is transformed into a museum.

\section{A Museum as an Example of a Play-Learning Environment}

In our museum there are different workstations: a reception desk and kiosk, the exhibition, and a coffee shop. Some children are staff in these centres, while others are the visitors to the museum. I will describe all these workstations/ centres and explain in detail what could happen there and identify connections to the formal curriculum (i.e., "curricular competencies" within the province of British Columbia; see Government of British Columbia, 2017). I will provide suggestions for PLE time, as well as address play-based practices consistent with a more traditional teaching approach still within the theme of the museum.

Children will circulate through the different roles, and teachers will appoint children into the different centres at different times. Therefore, teachers can make sure that all children have the opportunity to experience each role and learning activity happening at each centre. It is important to mention that teachers are not arranging the PLE on their own but together with the children. This in itself is a learning opportunity, and can be done with all the children or in smaller groups.

Exhibition. Part of our classroom is going to be the exhibition space. We can start collecting materials with children, give them homework to start a collection (maybe a few weeks prior to the planned start), or we can ask children to bring their collections from home. Each child can get their own collection space, or similar artefacts could be exhibited together. Picking artefacts to exhibit could be a whole-group activity or done in smaller groups. We can teach children how to do this by bringing many different objects to the classroom and ask the children how to group or sort them. We can talk about similarities and differences of the objects in the big group, but then divide children into smaller groups or pairs and give them pictures of the objects. Children can sort them and glue pictures of the ones they choose to exhibit in groups on bigger paper. After this work, all the children can discuss the different solutions to the problem and decide together how the collections should be exhibited. Exhibits can be described on cards, and the names of the children should also be written on these cards. This allows children to give tours through the exhibit, to read (in print or pictures) whom this exhibit belongs to, and to give information about where it was found, what it is, or why these things were chosen to collect. Working on the collection will probably fill several days. Possible curricular competencies we work on while doing this are speaking in front of the whole group, naming objects, comparing objects, counting, sorting, collaborating, problem solving, presenting possible solutions, and writing or drawing names/objects/places (Government of British Columbia, 2017). Once the artefacts are ready, we will need to discuss how they could be introduced in a tour to museum visitors. Children giving these tours need to read the cards or symbols, trying to remember what the children said about their exhibits, talk in front of other children, and answer questions. Experiencing a museum through a field trip with the class would be a great start for this PLE.

Visitors. Visitors to the museum can dress up as such (e.g., with shirts, skirts, jewellery, hats, scarves) and will need money to buy tickets and snacks, pay for tours, and visit the coffee shop. Visitors will work on their communication skills (e.g., how to buy a ticket and book a tour, what to ask the guide about the exhibits, how to order at the coffee shop), mathematical skills (e.g., counting, paying, checking change), as well as social skills (e.g., waiting in line, waiting for their turn to speak, taking turns, sharing).

Reception desk. Playing possibilities in the reception area include dressing up for work (a scarf or name tag, or 
similar); selling entry tickets, snacks, gift cards; maintaining statistics on how many tickets and snacks are sold; supplying customers with tickets or wrist bands; hanging up coats and handing out numbers. Children working at the reception desk will need to take turns, help each other dress up, use mathematical concepts like addition (multiple tickets), subtraction (customers with gift cards), and counting (money given, return money, things sold); and write or draw (tickets, wrist bands, coat numbers). There is also a lot of communication happening as staff need to address customers, tell them about the exhibition, and tell them about prices, tours, and the exhibition itself.

Coffee shop. In the coffee shop, children can prepare food and drinks. They need to be able to read the menu and to write or draw the customers' orders, calculate prices and return money (addition and subtraction), read recipes, collaborate, take turns, and help each other. Coffee shop staff can be dressed up too, and there could be different roles (e.g., cashier, barrista, server). The coffee shop can be extended into a full-on restaurant where actual food is prepared (e.g., sandwiches, fruit platters).

Extensions. Play-learning environments can be extended through additional centres (e.g., a gift shop, a workshop to develop new exhibits, or an office to design invitations or flyers, order materials, and keep statistics about materials used or number of visitors) or by inviting other grades or parents as visitors to the museum. A field trip to a museum or to other kinds of museums (e.g., an art gallery) could also be an extension of the PLE and could lead to a further PLE in the classroom.

\section{Teaching and Assessment in a Play-Learning Environment}

A play-learning environment is not one big centre where children play between blocks of direct instruction. Instruction takes place within the PLE and teachers integrate aspects of the formal curriculum. The ideas I provided above as examples cover curricular competencies for kindergarteners in career education, social studies, language arts, mathematics, and science (Government of British Columbia, 2017). Teaching happens within the PLE when new concepts are introduced, problems are discussed, and solutions are presented. A teacher can also introduce new concepts or assess children on an individual or group basis while they play in one of the areas of the PLE. This can be done through observation or through taking on a role and playing with the children. It is, however, important to note that the PLE needs to be introduced slowly and built up in collaboration with the children. New materials and activities should be introduced when children are comfortable in their play. Furthermore, children often develop their own ideas on how PLEs could be extended and improved.

Every day there should be time to play and work in the PLE, and teachers should appoint the roles for the children. As soon as the children play and work independently we can use this time to teach, observe, and evaluate their learning individually or in small groups. The best way to do this is for us, teachers, to take on a role ourselves and teach and assess the children from inside their play, not from the outside. That is, if we want to assess a child's mathematical knowledge, we could be a visitor and appoint the child to the reception desk. Through booking a tour, buying a ticket and snacks, and introducing gift cards, we can assess, not only a child's ability to add and subtract, but also their communication skills). It is important to note there should also be time for free play every day. This can happen in the PLE or in other centres (e.g., art, games, construction). During free play, children should be permitted to pick their role and to choose when, how long, and how often they want to play the same role within the PLE. Other school subjects can take place within the PLE. For example, art education can easily be a part of the museum PLE through integrating the children's art projects in the museum. Working in a PLE should not limit the activities within a classroom. Instead, it should provide a framework for learning and development, supporting my claim that instruction and play do not exclude each other. 


\section{Conclusion}

In summary, in this article I highlighted the importance of sociodramatic play in the development of preschool and early primary children for a successful transition to learning in school. I specified the characteristics of mature play and how teachers and educators can enhance, support, and scaffold children's play through mediating, coaching, suggesting, modelling, and, most essentially, providing sufficient time for play. Further, I discussed prospective teachers' and educators' questions on how to incorporate play in the everyday activities in their classrooms, and I gave an example of how sociodramatic play can be used to teach curricula. Through this I was able to challenge a belief I have encountered many times from my prospective ECE teachers: that play and instruction are separate activities and cannot be brought together. Providing references to curriculum should give teachers enough arguments to defend their choice of teaching through play. It is important to explain to parents what children are learning while playing, and that curricular goals are met through play. I acknowledge that playlearning environments require careful planning for learning and assessment, as well as teacher flexibility. I am aware that more questions exist regarding the incorporation of play in early childhood classrooms, and I look forward to many more fruitful discussions about ideas and ways to integrate play in curricula.

\section{References}

Achermann, E. (2009). Der vielfalt raum und struktur geben. Unterricht mit kindern von 4-8 jahren. Bern, Switzerland: Schulverlag Plus.

Bodrova, E., \& Leong, D. J. (2003). Learning and development of preschool children from the Vygotskian perspective. In A. Kozulin, B. Gindis, V. S. Ageyev, \& S. M. Miller (Eds.), Vygotsky's educational theory in cultural context (pp. 156-176). Cambridge, England: Cambridge University Press.

Bodrova, E., \& Leong, D. J. (2007). Tools of the mind: The Vygotskian approach to early childhood education (2 $2^{\text {nd }}$ ed.). Upper Saddle River, NJ: Pearson.

Burkhardt Bossi, C., Lieger, C. \& von Felten, R. (2009). Spielen als lernprozess. Zürich, Switzerland: Verlag Pestalozzianum.

Gajdamaschko, N. (2011). Lev Vygotsky's theories in education. EDUC 879-G001 Spring 11 Graduate Seminar. Burnaby, BC: Simon Fraser University.

Government of British Columbia. (2017). BC’s new curriculum. Retrieved from: https://curriculum.gov.bc.ca/

Karpov, Y. V. (2003). Development through the lifespan. A neo-Vygotskian approach. In A. Kozulin, B. Gindis, V. S. Ageyev, \& S. M. Miller (Eds.), Vygotsky's educational theory in cultural context (pp. 138-153). Cambridge, England: Cambridge University Press.

Kravtsov, G. G., \& Kravtsova, E. E. (2010). Play in L. S. Vygotsky's nonclassical psychology. Journal of Russian and East European Psychology, 48(4), 25-41. doi: 10.2753/RPO1061-0405480403

Smidt, S. (2009). Introducing Vygotsky. A guide for practitioners and students in early years education. London, England: Routledge.

Vygotsky, L. S. (1978). Mind in society: The development of higher psychological processes. Cambridge, MA: Harvard University Press. 